\title{
ISOLASI DAN IDENTIFIKASI GOLONGAN SENYAWA KIMIA FRAKSI DIETIL ETER DAUN BERUWAS LAUT (Scaevola taccada (Gaertn.) Roxb.) ASAL KABUPATEN PINRANG (SULAWESI SELATAN)
}

\author{
Rachmat Kosman, Kurniati Tappang \\ Fakultas Farmasi Universitas Muslim Indonesia \\ Email : rachmatkosman@gmail.com
}

\begin{abstract}
Isolation and identification of the chemical compound diethyl ether was done at beruwas laut leaves. Extraction is carried out using methanol and then partitioned with diethyl ether. Fraction of diethyl ether then isolated by column chromatography method using adsorben and n-hexane: ethyl acetate (3:7) as the elution fluid. Then obtained 30 fractions by color and by KLT profiles obtained 16 fractions. dominant fraction with patches further purified by preparative $K L T$ to obtain the pure compound. Tape I at $366 \mathrm{~nm}$ UV rays were analyzed by ultraviolet-visible spectroscopy showed maximum absorption at a wavelength of $239.5 \mathrm{~nm}$ as measured from wavelength $200-800 \mathrm{~nm}$. Whereas isolates infrared spectroscopic data allow hydroxy, aromatic, and alkyl ketones. Whereas chemical reactions showed positive flavanoid compounds.
\end{abstract}

Key Words : Isolation and identification, fractions of diethyl ether, Scaevola taccada (Gaertn.) Roxb.

\section{PENDAHULUAN}

Indonesia merupakan salah satu negara kepulauan yang memiliki bermacam spesies tumbuhan. Bangsa Indonesia secara turun temurun menggunakan tumbuhan sebagai pengobatan sebelum mengenal obatobat modern.

Sekarang ini banyak orang memilih untuk mengkonsumsi obat herbal karena menganggap obat herbal lebih aman dari pada obat sintetis. Selain itu obat herbal minim efek samping dan sisi kekayaan alam
Indonesia, obat herbal sangat mudah dicari. Sehingga jika dikonsumsi dalam jangka panjang tidak akan menimbulkan komplikasi dalam tubuh. Namun demikian, dalam perkembangannya seiring dijumpai ketidaktepatan paracikan obat herbal karena kesalahan informasi. Juga adanya anggapan yang keliru terhadap obat herbal dan cara penggunaanya, sehingga dalam beberapa kasus menimbulkan efek samping. Sawi laut ditemukan di pantai-pantai tropis di Samudra Pasifik 
dan India. Karena tersebar di beberapa daerah sawi laut yang juga di sebut dengan Scaevola taccada memiliki nama lokal yang berbeda beda. Di Hawaii, hal itu disebut naupaka kahakai. Hal ini merupakan pertimbangan karena tempat tumbuhnya banyak disepanjang garis pantai naupaka (Mosquin, 2008)

Daun tumbuhan Sawi Laut (Scaevola taccada (Gaertn.) Roxb.) digunakan sebagai obat antihipertensi, antidiabetik serta infeksi pada mata oleh masyarakat pinrang Sulawesi selatan.

\section{METODE PENELITIAN}

\section{A. Alat dan Bahan}

Alat yang digunakan adalah botol coklat, chamber, Erlenmeyer, gelas kimia, gelas ukur, lampu UV 254 nm, lampu UV 366, pipa kapiler, seperangkat alat maserasi, seperangkat alat KLT, seperangkat alat kromatografi kolom cair vakum, seperangkat alat KLTP, spektroskopi IR, spektroskopis UVVis, Timbangan analitik, Vial.

Bahan-bahan yang digunakan pada penelitian ini adalah air suling, aseton, benzene, daun sawi laut (Scaevola taccada (Gaertn.) Roxb.), dietil eter, etil asetat, kloroform, methanol. Nheksan, pelat $\mathrm{KLT}$, pelat KLTP, penampakan bercak : asam fosfat, Dragendrof, Liebermann-Burchard, Silika Gel.

\section{B. Prosedur Kerja}

\section{Ekstraksi Sampel}

\section{a. Ekstraksi secara maserasi dengan pelarut etanol}

Sampel kering yang telah dipotong-potong diambil dan ditimbang sebanyak 1000 gram kemudian dimasukkan kedalam wadah untuk di maserasi (masing-masing wadah berisi $500 \mathrm{mg}$ sampel), kemudian ditambahkan etanol (hingga simplisia tersebut terendam) dibiarkan selama 5 hari dalam bejana tertutup dan terlindungi dari cahaya matahari dambil diaduk sesering mungkin. Setelah itu simplisia disaring dan ampasnya direndam lagi dengan pelarut etanol yang baru, penyarian dilakukan selama tiga kali. Hasil penyarian yang diperoleh kemudian diuapkan dengan cara diangin-anginkan hingga diperoleh ekstrak etanol. 
b. Ekstraksi dengan pelarut Dietil-eter

$$
\text { Ekstrak etanol }
$$

ditimbang sebanyak 5 gram, dimasukkan kedalam Erlenmeyer $250 \quad \mathrm{ml}$ kemudian ditambahkan dengan dietil eter sebanyak $25 \mathrm{ml}$. Kemudian diaduk dengan pengaduk magnetik. Ekstrak yang larut dalam dietil eter dikeluarkan dari labu dan ke dalam labu ditambahkan lagi dietil eter yang baru lalu diaduk. Proses partisi padat cair ini dilakukan hingga pelarut dietil eter yang ditambahkan menjadi bening. Ekstrak larut dietil eter dikumpulkan, pelarutnya diuapkan hingga diperoleh Fraksi dietil eter kental.

\section{Identifikasi dengan KLT}

a. Isolasi dengan metode Kromatografi Kolom Konvensional

$$
\begin{aligned}
& \text { Fraksi Daun Beruwas } \\
& \text { Laut (Scaevola taccada } \\
& \text { (Gaertn.) Roxb.) diisolasi } \\
& \text { secara kromatografi kolom } \\
& \text { konvensional dengan fase } \\
& \text { diam berupa silica gel G.60 }
\end{aligned}
$$

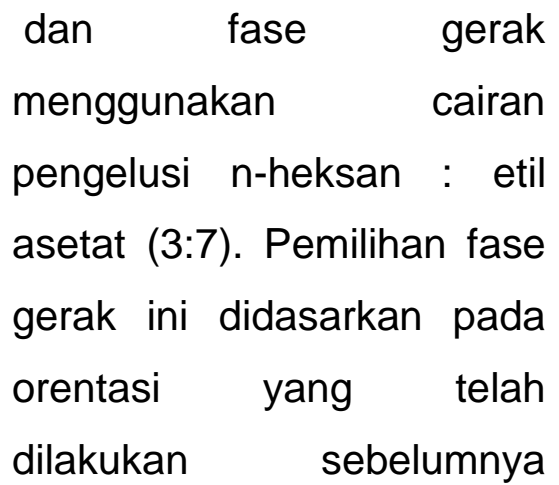
menggunakan kromatografi lapis tipis. Kolom dibebas lemakkan dengan cara membilas dengan metanol, sumbat bagian bawah kolom dengan kapas. Silica gel disuspensikan dengan nheksan yang telah disiapkan. Suspensi itu kemudian dituangkan ke dalam kolom, selama proses pengendapan kolom diketuk-ketuk tiap sisinya agar tidak terbentuk gelembung gas dan diperoleh kerapatan kolom yang seragam. Ekstrak yang akan difraksinasi tersebut diletakkan diatas permukaan silca gel secara merata. Setelah itu eluen dialirkan dan fraksi-fraksi yang diperoleh ditampung pada vial yang disediakan. Fraksi di identifikasi dengan kromatografi lapis tipis dan 
yang memberikan profil kromatogram yang sama disatukan dalam satu fraksi.

b. Kromatografi Lapis Tipis Preparative

Fraksi Daun Beruwas laut (Scaevola taccada (Gaertn.) Roxb.) hasil dari kromatografi kolom ditotolkan pada lempeng KLTP dengan ukuran $10 \mathrm{x}$ $10 \mathrm{~cm}$, selanjutnya dielusi dalam chamber yang berisi eluen n-heksan:etil asetat (8:2). Jika elusinya sudah mencapai batas, lempeng tersebut dikeluarkan dan dikeringkan di udara kemudian diamati dibawah sinar UV 254 nm dan 366 $\mathrm{nm}$. Lempeng yang telah diamati diberi batas noda dan dikeruk, lalu ditampung pada vial. Hasil kerukan tersebut selanjutnya ditambahkan pelarut methanol absolut kemudian disaring. Filtrat diuapkan lalu ditambahkan kembali dengan pelarut methanol absolut kemudian filtrat ditotolkan pada lempeng KLT, selanjutnya dielusi dengan eluen $n$-heksan-etil asetat (8:2). Jika proses elusi selesai kemudian diamati di bawah sinar UV 254 nm dan 366 nm. Dan menghasilkan 1 noda tunggal yang menandakan isolat tunggal.

c. Uji kemurnian isolat

1) Kromatografi Lapis Tipis Dua Dimensi

Isolat yang telah didapat kemudian ditotol lempeng kromatografi lapis tipis dengan ukuran $10 \times 10 \mathrm{~cm}$. Ialu dielusi dengan cairan pengelusi. Untuk proses elusi yang pertama dilakukan dengan cara menotolkan isolat yang telah dilarutkan dengan pelarut yang sesuai dengan lempeng kemudian dielusi dengan menggunakan eluen $\mathrm{n}$ heksan-etil asetat (8:2). Proses elusi yang kedua dengan cara memutar lempeng berlawanan arah jarum jam sehingga hasil elusi yang pertama menjadi titik awal pengelusian untuk yang kedua dengan 


$$
\begin{aligned}
& \text { menggunakan eluen n- } \\
& \text { Heksan : etil asetat (7:3). } \\
& \text { Apabila pada dua kali } \\
& \text { proses elusi ini hanya } \\
& \text { menunjukkan satu } \\
& \text { bercak tunggal maka } \\
& \text { dapat dikatakan bahwa } \\
& \text { isolat yang didapatkan } \\
& \text { adalah komponen yang } \\
& \text { tunggal. } \\
& \text { 2) Kromatografi Lapis } \\
& \text { Tipis Multi Eluen } \\
& \text { Uji kemurnian } \\
& \text { bercak tunggal juga } \\
& \text { dilakukan dengan } \\
& \text { menggunakan beberapa } \\
& \text { variasi cairan pengelusi } \\
& \text { yaitu n-heksan : etil } \\
& \text { asetat (8:2), n-Heksan : } \\
& \text { etil asetat (7:3) dan } n \text { - } \\
& \text { heksan : kloroform (2:6). } \\
& \text { Penampakan bercak } \\
& \text { tunggal menandakan } \\
& \text { bahwa golongan } \\
& \text { senyawa dari isolat yang } \\
& \text { diperoleh merupakan } \\
& \text { golongan komponen } \\
& \text { kimia yang tunggal. }
\end{aligned}
$$

\section{Identifikasi sampel}

Isolat murni yang diperoleh kemudian ditotolkan pada pelat KLT dan dielusi dengan n-heksan:etil asetat
(8:2). Hasil pengelusi kemudian disemprotkan dengan penampakan bercak golongan komponen kimia. Penampakan bercak yang digunakan yaitu Antimon (III) Klorida, Benedict.

\section{Penentuan} dengan

\section{spektrofotometri UV-Visible}

Senyawa murni yang

diperoleh

kemudian

diidentifikasi dengan

Spektrofotometri UV-Visible.

Senyawa dilarutkan dalam metanol absolut kemudian sampel ditempatkan diantara monocromator dan detector. Spektrum yang dihasilkan direkam pada alat pencatat.

5. Penentuan dengan spektrofotometri Inframerah (IR)

Senyawa murni yang diperoleh kemudian diidentifikasi dengan Spektrofotometri Inframerah dengan cara menempatkan cuplikan sebagai film yang tipis diantara dua lapisan natrium klorida yang transparan, kemudian ditempatkan pada celah sinar inframerah. Hasilnya direkam pada alat pencatat. 


\section{HASIL PENELITIAN}

Tabel 1. Nilai Rf dan Warna Bercak Pada Profil Kromatogram Fraksi Dietil eter Daun Beruwas Laut (Scaevola taccada (Gaertn.) Roxb.)

\begin{tabular}{ccccccc}
\hline \multirow{2}{*}{ Bercak } & \multicolumn{3}{c}{ Nilai RF } & \multicolumn{3}{c}{ Warna Bercak } \\
\cline { 2 - 7 } & UV 254 nm & UV 366 nm & Uap lod & UV 254 nm & UV 366 nm & Uap lod \\
\hline 1 & 0,8363 & 0,7818 & 0,8181 & Hijau & MerahMuda & Kuning \\
2 & 0,6909 & 0,7090 & 0,7090 & Hijau & MerahMuda & Kuning \\
3 & 0,6363 & 0,5818 & 0,5636 & Hijau & Biru & Hijau \\
4 & 0,5818 & 0,4909 & 0,4727 & HijauKekuningan & Biru & Ungu \\
5 & 0,4909 & 0,4181 & 0,3818 & HijauKekuningan & Ungu & Ungu \\
6 & 0,4 & 0,3454 & 0,3090 & Hijau & Ungu & Hijau \\
7 & 0,3272 & 0,1818 & 0,2363 & Hijau & MerahMuda & Kuning \\
8 & 0,1818 & - & - & Hijau & - & - \\
\hline
\end{tabular}

Tabel 2. Nilai Rf dan Warna Bercak Pada Kromatogram Hasil KLT-Preparatif Fraksi Dietil Eter Daun Beruwas Laut (Scaevola taccada (Geartn.) Roxb.)

\begin{tabular}{ccccc}
\hline \multirow{2}{*}{ Bercak } & \multicolumn{2}{c}{ Nilai RF } & \multicolumn{2}{c}{ Warna Bercak } \\
\cline { 2 - 5 } & UV 254 nm & UV 366 nm & UV 254 $\mathbf{~ m m}$ & UV 366 $\mathbf{~ m ~}$ \\
\hline Rf 1 & 0,7058 & 0,6470 & Biru & Hijau \\
Rf 2 & 0,5882 & 0,4705 & Biru & Ungu \\
Rf 3 & 0,45882 & 0,3647 & Hijau & Ungu \\
Rf 4 & 0,3529 & 0,1764 & Hijau & Ungu \\
Rf 5 & 0,2352 & - & Hijau & - \\
Rf 6 & 0,1411 & - & Hijau & - \\
\hline
\end{tabular}

\section{PEMBAHASAN}

Beruwas Laut (Scaevola taccada (Gaertn.) Roxb.) dapat mencapai tinggi hingga 3-4 $\mathrm{m}$. Daun melebar kearah atas. Berwarna hijau kekuningan dan mengkilat, tepinya melengkung dan permukaan daun seperti berlapis lilin. Unit dan letaknya sederhana dan bersilangan. Bentuk bulat telur terbalik hingga elips. Ujungnya membundar. Letak bunga di ketiak daun dan formasinya mengelompok. Daun mahkota putih bersih, sering pada bagian dalamnya terdapat strip/garis berwarna jingga. Tangkai Putik membengkok. Buah
Berbentuk kapsul, bulat. Ketika muda berwarna hijau muda, lalu menjadi putih ketika sudah matang. Ukuran buah diameter buah 8-12 $\mathrm{mm}$. Sementara Ekologinya biasa Dijumpai secara soliter di bagian tepi daratan dari mangrove, pada tepi pematang yang tidak terkena pengaruh pasang surut atau di daerah yang system drainasenya baik dan lokasinya terbuka terhadap cahaya. Ditemukan di beberapa garis pantai sebagian daerah Indonesia.

Dalam penelitian ini digunakan daun Beruwas Laut (Scaevola taccada (Gaertn.)Roxb.) karena secara empiris 
Isolasi Dan Identifikasi Golongan Senyawa Kimia Fraksi Dietil Eter Daun Beruwas Laut

Beruwas Laut digunakan oleh masyarakat Kabupaten Pinrang sebagai antihipertensi, anti diabetes serta infeksi pada mata. Serta berdasarkan penelitian sebelumnya beruwas laut berkhasiat sebagai antidiabetes, antiinflamasi, hepatoprotektor, immunoglobulin G, serta antioksidan. Agar penggunaannya optimal, perlu diketahui informasi yang memadai tentang kandungan kimia dari beruwas laut (Scaevola taccada (Gaertn.) Roxb.).

Metode ekstraksi yang digunakan adalah maserasi, yang merupakan metode ekstraksi dingin. Metode ini tidak merusak komponen kimia pada daun Beruwas Laut, karena tidak adanya pemanasan yang terjadi dalam proses ekstraksi. Pelarut yang digunakan etanol 96\%, karena etanol merupakan pelarut semipolar yang dapat menarik komponen polar dan non polar. Selain itu etanol tidak bersifat toksik. Ekstrak etanol kental yang diperoleh selanjutnya di partisi padat-cair dengan menggunakan pelarut dietileter dimana dapat menarik senyawa yang bersifat non polar. Metode ini digunakan berdasarkan karakteristik ekstrak yang tidak larut dalam air.Metode isolasi yang digunakan adalah kromatografi kolom konvensional karena metode ini pengerjaan dan alat yang digunakan lebih sederhana. Selain itu pemisahan komponen kimia sampel lebih sempurna. Adapun cairan pengelusi yang digunakan yaitu $n$-Heksan : Etil Asetat (3:7) karena berdasarkan pemilihan eluen sebelumnya cairan pengelusi ini dapat mengelusi sampel dengan baik sehingga diperoleh fraksi 30 fraksi berdasarkan warna serta 16 fraksi berdasarkan profil KLT.

Pemisahan dan pemurnian senyawa dilanjutkan dengan Kromatografi Lapis Tipis Preparatif sehingga didapatkan 6 pita pada sinar UV $254 \mathrm{~nm}$ serta 4 pita pada sinar UV $366 \mathrm{~nm}$.

Isolat I pada penampak bercak sinar UV $366 \mathrm{~nm}$ kemudian dilanjutkan dengan uji kemurnian menggunakan $K L T$ multi eluen dengan variasi eluen n-Heksan : etil asetat (8:2), n-Heksan : Kloroform (2:6) dan n-Heksan : etil asetat (7:3). Hasil elusi tersebut menampakkan noda tunggal yang dapat dilihat dengan menggunakan UV $366 \mathrm{~nm}$. Selain itu dilakukan dengan system KLT Dua Dimensi mengunakan dua variasi eluen yaitu $\mathrm{n}$ Heksan : etil asetat (8:2) untuk arah pertama dan $\mathrm{n}$-Heksan : etil asetat (7:3) untuk arah kedua diperoleh bercak tunggal, sehingga 
kemungkinan besar isolate telah murni.

Identifikasi dengan reaksi kimia yaitu dengan pereaksi Antimon (III) klorida tampak bercak berpendar dalam sinar UV $366 \mathrm{~nm}$, pada pereaksi Tembaga sulfat-sitrat (pereaksi Benedict) mengurangi pendaran dalam sinar UV 366 nm. Hasil reaksi terjadi pada pereaksi-pereaksi tersebut dengan bercak tunggal pada isolate menunjukkan bahwa bercak tunggal tersebut masuk kedalam golongan flavanoid. Interpretasi data spektrofotomerter UV Visible menunjukkan serapan maksimum pada panjang geolombang $239,50 \mathrm{~nm}$. Sedangkan interpretasi data spektrofotometer Infra Merah menunjukkan panjang gelombang $3364.54 \mathrm{~nm}$ menunjukkan adanya gugus hidroksi $(\mathrm{OH})$, panjang gelombang 1577, $19 \mathrm{~nm}$ menunjukkan adanya cincin aromatis, panjang gelombang 1413,02 nm menunjukkan adanya gugus alkil, pada panjang gelombag 1119,59 menunjukkan adanya gugus keton.

\section{KESIMPULAN}

Dari hasil penelitian maka dapat disimpulkan bahwa golongan komponen kimia yang terdapat pada fraksi dietil eter daun Beruwas Laut (Scaevola taccada (Gaertn.)Roxb.) adalah golongan Flavanoid dengan panjang gelombang $239.50 \mathrm{~nm}$ dan memiliki gugus hidroksi, aromatis, keton, alkil serta didukung penampak bercak setelah penyemprotan pereaksi benedict dan pereaksi Antimon (III) klorida.

\section{DAFTAR PUSTAKA}

Adnan, M. 1997. "Teknik Kromatografi". Penerbit Andi. Yogyakarta

Bambang, S. 1993. "Pereaksi Kromatografi Lapis Tipis". Fakultas Farmasi Universitas Pancasila. Jakarta

Daniel Mosquin, 2008, Scaevola taccada (Online), http://www.ntbg.org/plants/plant details.php?plantid $=10272$.Dia kses 28 September 2011)

Direktorat Jenderal Pengawasan Obat dan Makanan. 1986. "Sediaan Galenik". Departemen Kesehatan Republik Indonesia. Jakarta

Direktorat Jenderal Pengawasan Obat dan Makanan, 1987. "Analisis Obat Tradisional". Departemen Kesehatan Republik Indonesia. Jakarta

Dirjen POM., 1979. "Farmakope Indonesia". Edisi III, Departemen Kesehatan RI, Jakarta.

Gritter, J.R. 1991. "Pengantar Kromatografi". Terjemahan Padmawinata, EdisiKedua, ITB, Bandung

Harborne, J. B. 1987. "Metode Fitokimia, Penuntun Cara 
Modern Mengekstraksi

Tumbuhan". Terjemahan

Padmawinata, K. Edisi II.

Penerbit ITB. Bandung

Hean Chooi Ong, 2004, Tumbuhan liar : khasiat ubatan \& kegunaan (Online), http:/ /www.scribd.com/doc/64909444 IBio-Divers-It-As Diakses 8Oktober 2011)

Hendayana, Sumar. 2006. "Kimia Pemisah". PT. Remaja Rosda karya. Bandung

Hostettmann, K., 1985 ."Cara Kromatografi Preparatif, Penggunaan Padalsolasi Senyawa Alam". ITB, Bandung

LIPI, 2011. "Hasill denditifikasi / Determinasi Tumbuhan Beruwas Laut". Pusat Penelitian Biologi". Bogor

Maysatria, Yamato. 2011, Scaevola taccada (Online), http: //muherda.blogspot.com/2011/ 02/scaevola-taccada.html, Diakses 8, Oktober 2011)
Sastroamidjoyo,

$\mathrm{H}$. 1989 "Kromatografi".Edisi II. Liberti. Yogyakarta

Stahl, Egon. 1985. "Analisis Obat Secara Kromatografi dan Mikroskopik". ITB. Bandung

Sudjadi, H.S. 1986. "Metode Pemisahan". Kanisius. Jakarta

Sudjadi. 2008. "Kimia Farmasi analisis". Pustaka Pelajar. Yogyakarta

Rohman, Abdul. 2009. "Kromatografi Untuk Analisis Obat". Grahallmu. Yogyakarta

Wikipedia, 2011, ,Scaevola taccada (Online), http ://en.wikipedia.org/w/index.php? title $=$ Scaevola taccada\&action $=$ edit\&redlink=1, Oktober 2011)

Wardini, T.H.,2011, Medicinal and poisonous plants (Online) http://www.proseanet.org/floraki ta/browser.php?docsid=747 , Diakses 7 Oktober 2011) 